\title{
Parenting Experiences of Cancer Patients with Minor Children and Their Conversations About the Possibility of Death: A Cross-Sectional Web-Based Survey for an Online Cancer Community
}

\section{Yuko Usui}

National Cancer Center-Hospital East: Kokuritsu Gan Center Higashi Byoin

Kazuhiro Kosugi

National Cancer Center-Hospital East: Kokuritsu Gan Center Higashi Byoin

Yohei Nishiguchi

General Incorporated Association Cancer Parents

Tomofumi Miura ( $\square$ tomiura@east.ncc.go.jp )

National Cancer Center-Hospital East: Kokuritsu Gan Center Higashi Byoin https://orcid.org/00000002-7031-7279

\section{Daisuke Fujisawa}

Keio University School of Medicine Graduate School of Medicine: Keio Gijuku Daigaku Igakubu

Daigakuin Igaku Kenkyuka

\section{Yuko Uehara}

Juntendo University Graduate School of Medicine

\section{Takashi Kawaguchi}

Tokyo University of Pharmacy and Life Science: Tokyo Yakka Daigaku

\section{Kayo Izumi}

Medilead Inc.

Jun Takehana

Medilead Inc.

\section{Yoshihisa Matsumoto}

National Cancer Center-Hospital East: Kokuritsu Gan Center Higashi Byoin

\section{Research Article}

Keywords: Cancer patients, cancer parents, minor children, the possibility of death

Posted Date: January 10th, 2022

DOI: https://doi.org/10.21203/rs.3.rs-1094874/v1 
License: (c) (i) This work is licensed under a Creative Commons Attribution 4.0 International License. Read Full License

Version of Record: A version of this preprint was published at Annals of Oncology on November 1st, 2019. See the published version at https://doi.org/10.1093/annonc/mdz430.001. 


\section{Abstract \\ Purpose}

Many cancer patients with minor children experience difficulty when talking about their illness with their children. The aim of this study is to investigate the parenting experiences of cancer patients with minor children and their conversations about the possibility of death.

\section{Methods}

A cross-sectional web-based survey was conducted between April and May 2019. Cancer patients with minor children were recruited from among an online peer support group called "Cancer Parents". The participants were asked to complete a questionnaire about their experiences talking about their illness with their children. The participants were classified into those who disclosed their cancer to their children ("disclosed group"), and those who didn't disclose ("undisclosed group"). The association between whether they talked with their children about their cancer and their conversations about the possibility of death were examined.

\section{Results}

A total of 370 participants were analyzed ( $80.8 \%$ female, median age 43.0 years). The disclosed group ( $\mathrm{n}$ $=274,74.1 \%)$ wanted to know what their child felt than the undisclosed group $(p<0.001)$. The undisclosed group didn't want their children to see their suffering $(p=0.002)$ and didn't know how to explain their disease condition $(p<0.002)$. Both the disclosed $(42.1 \%)$ and undisclosed $(6.5 \%)$ groups told their children about the possibility of death.

\section{Conclusion}

This study showed the disclosed group wanted to know their children's feelings and they tended to have a conversation about the possibility of death with their children, compared to the undisclosed group.

\section{Introduction}

Cancer is one of the leading causes of death in the world. Among deceased people aged 25-44 years old in the United States, $13 \%$ died from cancer.[1] The National Cancer Institute estimated that about $24 \%$ of adult cancer patients have minor children aged under 18 years.[2]

For parents with minor children, telling their children about their cancer was one of the predominant themes and difficult issues.[3,4] Parents with cancer struggled to tell their children about their own cancer and deal with their own feelings at the same time.[5] Cancer patients and their partners, as parents, have 
many concerns and anxieties about communicating with their children regarding the illness.[6] Similarly, their children wanted to know what was happening within their families during the illness. They usually wanted a frank conversation with their parents about the illness.[4] A previous study showed that the level of anxiety in children who were informed about their parent's cancer was significantly lower than those who were not informed.[7] Moreover, an inability to discuss their parent's cancer worsened anxiety in adolescents.[8] Most previous studies focused on difficulties and feelings in parents who had already told their children about their own cancer. Knowing how parents with cancer felt and whether or not they had conversations about death with their offspring may be helpful for healthcare professionals in order to provide personalized care.

The aim of this study was to clarify: 1) the proportion of parents who disclosed their cancer to their children, 2) the parents' feelings toward their children, and 3) the conversations about the possibility of death between the parents and their children.

\section{Methods}

\section{Study Design:}

This study was a sub-analysis of a cross-sectional web-based survey with self-administered questionnaires. A detailed methodology was previously described.[9]

\section{Participants:}

The eligibility criteria for participation in this study were: 1) clinically diagnosed with cancer, 2) a member of the online peer support community "Cancer Parents", 3) aged 20 years or older, and 4) had children aged under 18 years old. Participants who were unable to understand the questionnaire were ineligible.

"Cancer Parents" (https://cancer-parents.com/) is one of the largest online peer support groups for cancer patients with children in Japan. "Cancer Parents" had more than 3,000 cancer patients as active users of this group (as of February 5, 2020). Members can create/read posts, and connect to and exchange messages with peers.

\section{Procedures:}

This study was conducted between April 27 and May 13,2019. The details of the survey and the questionnaire URL were sent via e-mail to the members of "Cancer Parents" using a web survey system hosted by Medilead Inc. (http://www.medi-I.com). Participants anonymously accessed and answered the questionnaire.

\section{Measurements:}

An online questionnaire form was developed, which was based on previous literature.[10-12] The questionnaire was completely anonymous, and it included age, sex, primary cancer site, cancer stage, number of children, age of first child, disclosure of their own cancer to their children, feelings toward their 
children, and conversations about the possibility of death with their children. Feelings toward their children were evaluated using a 4-point Likert scale (1, strongly disagree; 2 , disagree; 3 , agree; 4, strongly agree). Five options were provided for the question regarding conversations about the possibility of their own death: "I told my children myself", "I was asked by my children and told them", "I was asked by my children but refused to answer them", "It has never been discussed", and "I have never thought of such a possibility".

\section{Statistical Analysis:}

Continuous variables were expressed as a median with an interquartile range (IQR). In the analysis using a 4-point Likert scale, responses of 1 (strongly disagree) and 2 (disagree) were classified as disagree, and those of 3 (agree) and 4 (strongly agree) were classified as agree. Respondents who disclosed their cancer to their children were defined as the "disclosed group" and those not disclosing as the "undisclosed group".

A chi-square test was utilized to analyze the association between disclosing their cancer to their children, and their experiences or conversations about the possibility of death. All analyses were conducted using JMP software (version 11.2; SAS Institute, Cary, NC).

\section{Results}

\section{Respondents' characteristics:}

A total of 3012 patients were eligible, and a total of 370 participants were analyzed (response rate: 12.5\%) (Fig. 1). Respondents' baseline characteristics are shown in Table 1. The median age of the participants was 43 years (IQR, 39-47 years) and 299 (80.8\%) were female. The most common primary cancer site was breast (34.3\%), followed by the colorectal region (11.9\%), and gynecological organs (11.4\%), and 103 participants (27.8\%) were diagnosed as having stage 4 cancer. The median number of children was two (IQR, one-two), and the median age of the first child was 11 years (IQR, 7-16 years). Among the subjects, 274 (74.1\%) disclosed their cancer to their children. 
Table 1

Participants' characteristics $(n=370)$

\begin{tabular}{|lllr|}
\hline & & $n$ & $\%$ \\
\hline Sex & Male & 71 & 19.2 \\
\hline Age & Female & 299 & 80.8 \\
\hline Primary cancer site & Median (IQR*) & $43(39-47)$ \\
\hline & Breast & 127 & 34.3 \\
\hline & Colorectal & 44 & 11.9 \\
\hline Stage & Gynecological & 42 & 11.4 \\
\hline & Others & 157 & 42.4 \\
\hline & I & 92 & 24.9 \\
\hline Number of children & II & 85 & 23.0 \\
\hline Age of first child & III & 59 & 15.9 \\
\hline Disclosed that they had cancer to their children & Disclosed & 274 & 74.1 \\
\hline & IV & 103 & 27.8 \\
\hline *IQR, interquartile range. & Median (IQR*) & $2(1-2)$ \\
\hline & Undisclosed & 96 & 25.9 \\
\hline
\end{tabular}

\section{Respondents' feelings toward their children:}

The respondents' feelings toward their children are shown in Table 2. The proportion of respondents that agreed with the statement "I want to know how my child feels" was higher in the disclosed group (85.4\%) than the undisclosed group (57.3\%) $(p<0.001)$ (Table 2). On the other hand, the proportion of respondents that agreed with the statement "I have no idea how to explain my disease condition." was higher in the undisclosed group (66.7\%) than the disclosed group $(28.1 \%)(p<0.001)$. The proportion of respondents that agreed with the statement "I do not want my minor children to see my suffering" tended to be higher in the undisclosed group (82.3\%) than the disclosed group $(72.6 \%)(p=0.059)$. 
Table 2

Participants' feelings for their children $(n=370)$

\begin{tabular}{|llllll|}
\hline & \multicolumn{2}{l}{ Disclosed } & \multicolumn{2}{l}{ Undisclosed } & \multirow{2}{*}{$\boldsymbol{p}^{*}$} \\
\cline { 2 - 5 } & $(\mathbf{n = 2 7 4 )}$ & \multicolumn{2}{l}{$(\mathbf{n = 9 6 )}$} & \\
\hline I am overwhelmed by other issues. & $\mathbf{n}$ & $\%$ & $\mathbf{n}$ & $\%$ & \\
\hline I have no idea how to interact with my children. & 29 & 10.6 & 15 & 15.6 & 0.189 \\
\hline It is distressing to interact with my children. & 27 & 9.9 & 14 & 14.6 & 0.204 \\
\hline I want to know how my children feel. & 234 & 85.4 & 55 & 57.3 & $<0.001$ \\
\hline I do not want my minor children to see my suffering. & 199 & 72.6 & 79 & 82.3 & 0.059 \\
\hline I have no idea how to explain my disease condition. & 77 & 28.1 & 64 & 66.7 & $<0.001$ \\
\hline
\end{tabular}

\section{Conversations about the possibility of death:}

The respondents in the disclosed group were more likely to agree with the statement "I told my children myself", "I was asked by my children and told them", and "I was asked by my children but refused to answer them" (Table 3).

Table 3

Conversations about the possibility of death with children $(n=366)$

\begin{tabular}{|c|c|c|c|c|c|}
\hline \multirow{3}{*}{$\begin{array}{l}\text { Have you ever told your children about the possibility of your } \\
\text { own death? }\end{array}$} & \multirow{2}{*}{\multicolumn{2}{|c|}{$\begin{array}{l}\text { Disclosed } \\
(n=273)\end{array}$}} & \multirow{2}{*}{\multicolumn{2}{|c|}{$\begin{array}{l}\text { Undisclosed } \\
(n=93)\end{array}$}} & \multirow[t]{3}{*}{$p^{*}$} \\
\hline & & & & & \\
\hline & $\mathbf{n}$ & $\%$ & $\mathbf{n}$ & $\%$ & \\
\hline I told my children myself. & 115 & 42.1 & 6 & 6.5 & \multirow{5}{*}{$\begin{array}{l}<.001 \\
0.001\end{array}$} \\
\hline $\begin{array}{l}\text { I was asked by my children and told } \\
\text { them. }\end{array}$ & 32 & 11.7 & 4 & 4.3 & \\
\hline I was asked by my children but refused to answer them. & 32 & 11.7 & 7 & 7.5 & \\
\hline It has never been discussed. & 64 & 23.4 & 53 & 57.0 & \\
\hline I have never thought of such a possibility. & 30 & 11.0 & 23 & 24.7 & \\
\hline
\end{tabular}

\section{Discussion}

The present study showed that: 1) a total of $74.1 \%$ of parents with minor children disclosed their cancer to their children, 2) the disclosed group wanted to know what their children felt, and 3) the disclosed 
group frequently had conversations about the possibility of death, compared to those in the undisclosed group.

The present study found that in both groups, parents with cancer had difficult feelings toward their children. The parents with cancer in the disclosed group were more likely to want to know how their children felt than those in the undisclosed group. On the other hand, most of those in the undisclosed group did not know how to explain their own disease to their children. A previous study reported that parents with cancer felt that they did not have sufficient knowledge to tell their children about their own cancer and wanted information from healthcare professionals.[13] Furthermore, patients with cancer felt unsupported by healthcare professionals and felt that they were not provided with enough advice on how to talk with their children about cancer.[14] Healthcare professionals supporting parents with cancer need to communicate to their patients about the disease, and about the difficulties parents face in communicating with their children. It is important for healthcare professionals to provide information tailored to the needs of each patient.

The disclosed group were more likely to have a conversation about the possibility of death with their children, while more than half of the undisclosed group never discussed the possibility of death with their children. The reason for this difference in results is unclear. A previous study reported patients' or their family members' difficulty in accepting a poor prognosis was an important barrier to discussing advanced care planning.[15] The present study found that there were more parents who had never thought of the possibility of death in the undisclosed group than the disclosed group. This suggests that some participants in the undisclosed group may not have fully accepted their cancer situation, including their prognosis. In addition, the present study showed that the undisclosed group had more parents who did not know how to explain their own disease condition. Parents with cancer may not know how honest they should be with their children, and be unsure of what is appropriate to share with them, and parents with advanced cancer found it difficult to answer their children's questions, including about their impending death.[16] Fathers with advanced cancer felt that they did not have the communication skills to talk about their situation with their children.[17] In addition, bereaved families who did not disclosure their terminal status to their children were more likely to feel distressed.[10] These previous studies suggest that parents with cancer and their family caregivers may find it difficult to tell their children about the possibility of death, and it is even more difficult for parents who did not disclose their cancer to their children. However, young adult children of terminal patients desired open and honest communication about cancer diagnosis, treatment, prognosis, and end-of-life care.[18] They also desired to create memories and spend quality time together with their parent before he/she died.[19] Adolescents with parents with cancer had difficulty taking the initiative in having conversations about their parents' situation.[20] If the children were not given honest information about the disease and its prognosis, they felt anxiety, loneliness, and sadness.[21] A multidisciplinary approach, such as Children's Lives Include Moments of Bravery (CLIMB), may be helpful to facilitate communication between parents with cancer and their children. CLIMB provides the opportunity to connect with other children who have parents with cancer, to share their feelings, and enhance their understanding of cancer.[22] While such an approach is useful, it presupposes that patients disclosed their cancer to their children and does not include patients 
who did not.[23] Cancer patients may benefit from online peer support networks, as an online peer support group, such as "Cancer Parents", could be an easily accessible resource that provides emotional support.[9]

This study had several limitations. First, the participants were favourable to using an online peer support, which may limit the ability to generalize the findings to diverse populations. Second, since this study was a self-administered web survey, the clinical information may not always be accurate. Third, there was a predominance of women in our sample (80\%), compared with previous studies.[24-27] Fourth, the percentage of respondents was small at about $10 \%$ of all the members of the website; thus, it was difficult to identify the number of all members who matched the inclusion criteria. Therefore, the findings may contain a response bias and self-selection bias.

Future research should investigate: 1) sex differences about feelings toward their minor children, and thoughts about telling them; and 2) what kinds of information and support help parents with cancer who did not disclose their illness to their minor children.

\section{Conclusion}

This study showed that $74.1 \%$ of patients with minor children disclosed their cancer to their children. The parents in the disclosed group wanted to know what their children felt and frequently had conversations about the possibility of death, compared to those in the undisclosed group. It is important for healthcare professionals treating cancer patients to understand their situations and problems to provide appropriate support to them.

\section{Declarations}

Funding: This study was funded by the Takeda Science Foundation.

Financial interest: The authors have no conflicts of interest to declare that are relevant to the content of this article.

\section{Author contributions:}

Yuko Usui: study design; development of questionnaire; analysis; writing manuscript; review; approval of manuscript

Kazuhiro Kosugi: study design; development of questionnaire; analysis; review; approval of manuscript

Yohei Nishiguchi: study design; development of questionnaire

Tomofumi Miura: study design; development of questionnaire; analysis; writing manuscript; review; approval of manuscript 
Daisuke Fujisawa: review; approval of manuscript

Yuko Uehara: review; approval of manuscript

Takashi Kawaguchi: study design; analysis; review; approval of manuscript

Kayo Izumi: analysis

Jun Takehana: analysis; review; approval of manuscript

Yoshihisa Matsumoto: review; approval of manuscript

Ethics approval: This study was conducted according to the Declaration of Helsinki and was approved by the Institutional Review Board of the National Cancer Center, Japan (approval number 2018-360).

Consent to participate: The questionnaire included the check box to declare disagree with participation. Therefore, participants who answered and returned the questionnaire without filling check box were considered to agree with participation.

Consent to publish: A letter of request explained the publication of this study. Therefore, participants who answered and returned the questionnaire were considered to agree with publication.

Availability of data and material: Not applicable.

Code availability: Not applicable.

Data sharing statement: Due to the sensitive nature of the questions asked in this study, survey respondents were assured raw data would remain confidential and would not be shared.

\section{References}

1. Minino AM (2013) Death in the United States, 2011 NCHS data brief: 1-8

2. Rauch PK, Muriel AC, Cassem NH (2002) Parents With Cancer: Who's Looking After the Children? J Clin Oncol 20:4399-4402

3. Semple CJ, McCance T (2010) Parents' experience of cancer who have young children: a literature review Cancer nursing. 33:110-118

4. Kennedy VL, Lloyd-Williams M (2009) Information and communication when a parent has advanced cancer. J Affect Disord 114:149-155

5. Barnes J, Kroll L, Burke O, Lee J, Jones A, Stein A (2000) Qualitative interview study of communication between parents and children about maternal breast cancer BMJ (Clinical research ed). 321:479-482

6. Bugge KE, Helseth S, Darbyshire P (2009) Parents' experiences of a Family Support Program when a parent has incurable cancer. J Clin Nurs 18:3480-3488 
7. Rosenheim E, Reicher R (1985) Informing children about a parent's terminal illness. J Child Psychol Psychiatry Allied Discip 26:995-998

8. Nelson E, Sloper P, Charlton A, While D (1994) Children who have a parent with cancer: a pilot study. Journal of cancer education: the official journal of the American Association for Cancer Education 9:30-36

9. Kosugi K, Nishiguchi Y, Miura T, Fujisawa D, Kawaguchi T, Izumi K, Takehana J, Uehara Y, Usui Y, Terada T, Inoue Y, Natsume M, Yajima MY, Watanabe YS, Okizaki A, Matsushima E, Matsumoto Y (2020) Association Between Loneliness and the Frequency of Using Online Peer Support Groups Among Cancer Patients With Minor Children: A Cross-Sectional Web-Based Study Journal of pain and symptom management

10. Hirooka K, Otani H, Morita T, Miura T, Fukahori H, Aoyama M (2018) End-of-life experiences of family caregivers of deceased patients with cancer: A nation-wide survey Psycho-oncology. 27:272-278

11. Muriel AC, Moore CW, Baer L, Park ER, Kornblith AB, Pirl W, Prigerson H, Ing J, Rauch PK (2012) Measuring psychosocial distress and parenting concerns among adults with cancer: the Parenting. Concerns Questionnaire Cancer 118:5671-5678

12. Pinquart M, Duberstein PR (2010) Associations of social networks with cancer mortality: a metaanalysis. Crit Rev Oncol/Hematol 75:122-137

13. Fearnley R, Boland JW (2017) Communication and support from health-care professionals to families, with dependent children, following the diagnosis of parental life-limiting illness: $A$ systematic review Palliative medicine. 31:212-222

14. Helseth S, Ulfsaet N (2005) Parenting experiences during cancer. J Adv Nurs 52:38-46

15. You JJ, Downar J, Fowler RA, Lamontagne F, Ma IWY, Jayaraman D, Kryworuchko J, Strachan PH, Ilan R, Nijjar AP, Neary J, Shik J, Brazil K, Patel A, Wiebe K, Albert M, Palepu A, Nouvet E, des Ordons AR, Sharma N, Abdul-Razzak A, Jiang X, Day A, Heyland DK, Network ftCRatEoL (2015) Barriers to Goals of Care Discussions With Seriously III Hospitalized Patients and Their Families: A Multicenter Survey of Clinicians JAMA Internal Medicine. 175:549-556

16. Kennedy VL, Lloyd-Williams M (2009) How children cope when a parent has advanced cancer Psycho-oncology. 18:886-892

17. Lundquist M (2017) Fathers Facing Advanced Cancer: An Exploratory Study Journal of social work in end-of-life \& palliative care. 13:266-283

18. Alvariza A, Lövgren M, Bylund-Grenklo T, Hakola P, Fürst CJ, Kreicbergs U (2017) How to support teenagers who are losing a parent to cancer: Bereaved young adults' advice to healthcare professionals-A nationwide survey Palliative \& supportive care 15: 313-319

19. Macpherson C, Emeleus M (2007) Children's needs when facing the death of a parent from cancer:. part one International journal of palliative nursing 13:478-485

20. Phillips F, Lewis FM (2015) The adolescent's experience when a parent has advanced cancer: A qualitative inquiry Palliative medicine. 29:851-858 
21. Buchwald D, Delmar C, Schantz-Laursen B (2012) How children handle life when their mother or father is seriously ill and dying Scandinavian. journal of caring sciences 26:228-235

22. Shallcross AJ, Visvanathan PD, McCauley R, Clay A, van Dernoot PR (2016) The effects of the CLIMB ${ }^{\circledR}$ program on psychobehavioral functioning and emotion regulation in children with a parent or caregiver with cancer: A pilot study. J Psychosoc Oncol 34:259-273

23. Ruddy KJ, Greaney ML, Sprunck-Harrild K, Meyer ME, Emmons KM, Partridge AH (2013) Young Women with Breast Cancer: A Focus Group Study of Unmet Needs. Journal of adolescent and young adult oncology 2:153-160

24. Inoue I, Higashi T, Iwamoto M, Heiney SP, Tamaki T, Osawa K, Inoue M, Shiraishi K, Kojima R, Matoba $M$ (2015) A national profile of the impact of parental cancer on their children in Japan Cancer epidemiology. 39:838-841

25. Nilsson ME, Maciejewski PK, Zhang B, Wright AA, Trice ED, Muriel AC, Friedlander RJ, Fasciano KM, Block SD, Prigerson HG (2009) Mental health, treatment preferences, advance care planning, location, and quality of death in advanced cancer patients with dependent children Cancer. 115:399-409

26. Ernst JC, Beierlein V, Romer G, Möller B, Koch U, Bergelt C (2013) Use and need for psychosocial support in cancer patients: a population-based sample of patients with minor children Cancer. 119:2333-2341

27. Park EM, Deal AM, Check DK, Hanson LC, Reeder-Hayes KE, Mayer DK, Yopp JM, Song MK, Muriel AC, Rosenstein DL (2016) Parenting concerns, quality of life, and psychological distress in patients with advanced cancer Psycho-oncology. 25:942-948

\section{Figures}




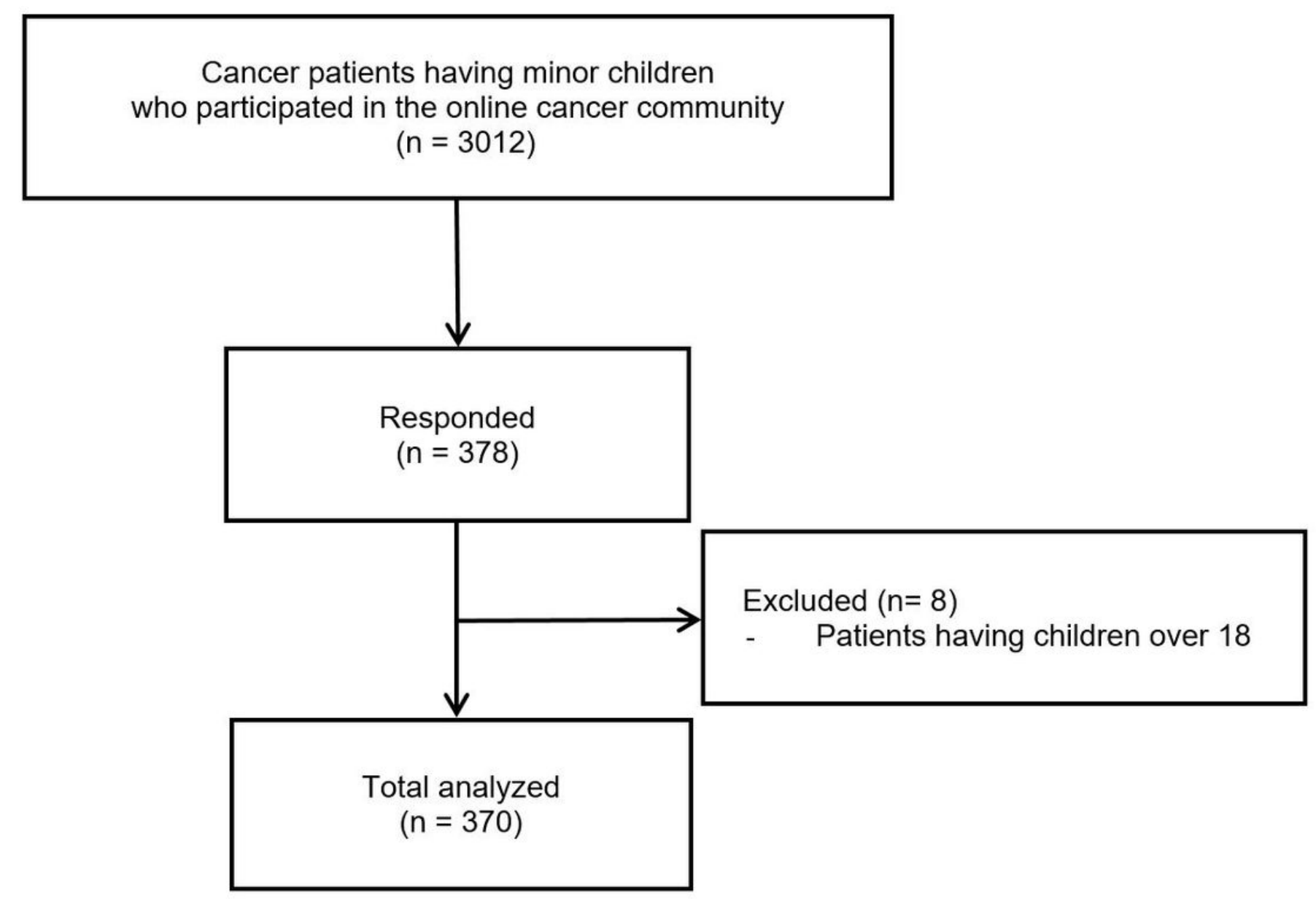

Figure 1

Participants flow according to STROBE statements $(n=3012)$ 